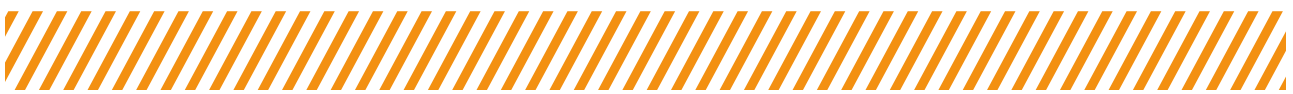

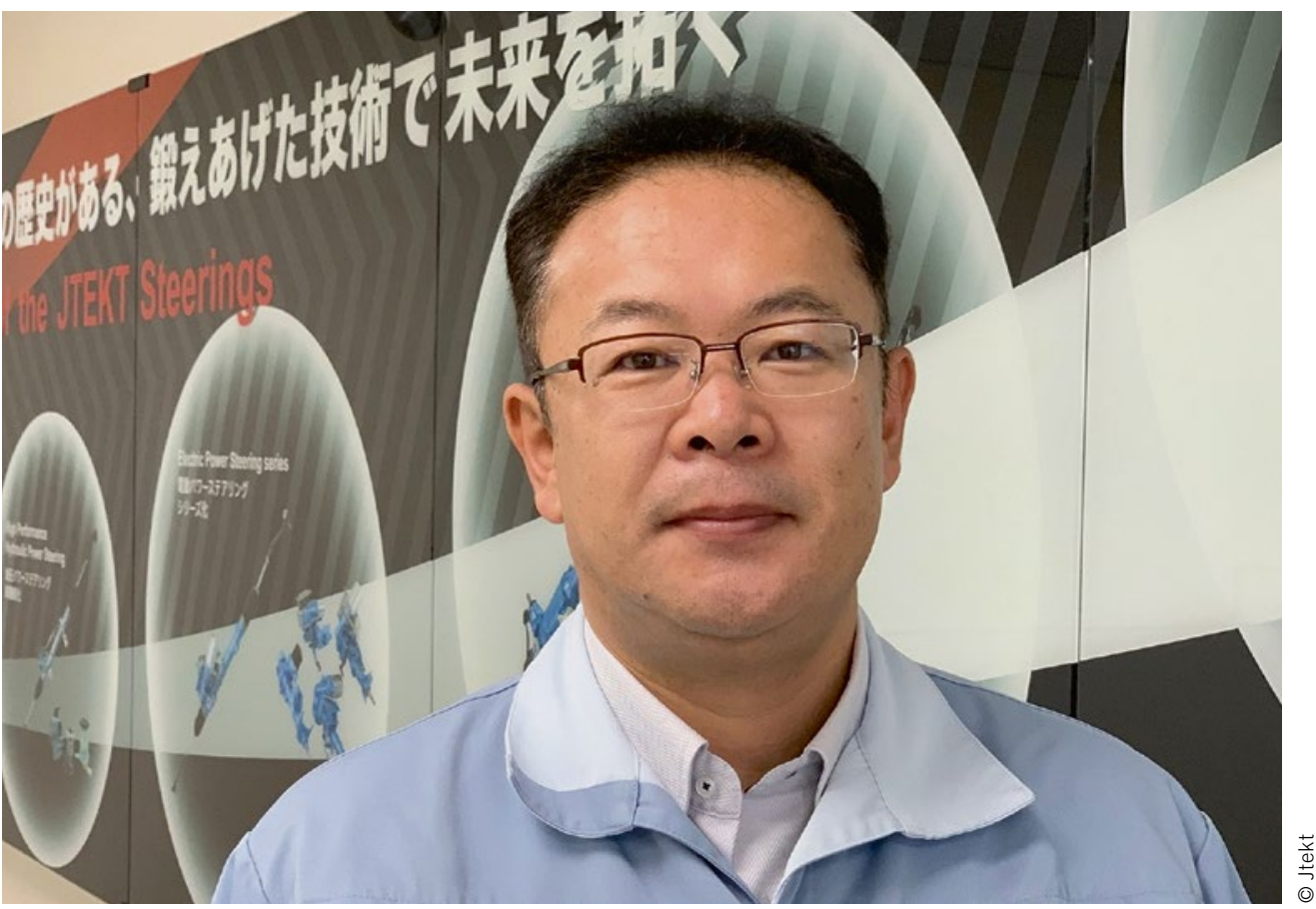

Yasuyuki Yoshii, B. Eng.

Leiter der Forschungsabteilung für Systeminnovation bei Jtekt

\section{Die Harmonisierung der Zusammenarbeit von Fahrer und Automatisierungssystemen}

Nach einer Phase, in der man den immensen Aufwand unterschätzt hatte, der nötig ist, um hochautomatisierte Fahrzeuge auf den Markt zu bringen, wurde 2019 mit dem Nissan Skyline das erste Fahrzeug eingeführt, das innerhalb einer Fahrspur dauerhaft freihändig gefahren werden kann. 2020 werden viele weitere OEMs Fahrzeuge mit einem Automatisierungsgrad nach SAE-Level 3 vorstellen; in Japan sollte dieser Trend besonders während der nun abgesagten Olympischen Sommerspiele von Tokio im Mittelpunkt stehen. Schon 1964 nutzte Japan die Tokioter Olympiade zur Einführung des Shinkansens, des weltweit ersten Hochgeschwindigkeitszugs. Sein Erfolg ist dank beispielloser Pünktlichkeit und dem Ausbleiben von Unfällen mit Todesfolge unbestritten. Die Debatte, ob das SAE-Level 3 übersprungen werden soll, scheint durch Tatsachen beendet. Entscheidend ist, dass die aktuelle Technik es noch nicht erlaubt, den Fahrer aus der Gleichung herauszukürzen. Automatisierung verspricht höhere Verkehrssicherheit und reduzierte Fahrerbelastung. Der Trend betrifft die Verkehrsmittel Flugzeug und Automobil. Allerdings standen die meisten der letzten Abstürze von Verkehrsflugzeugen und der Unfälle von SAE-Level-2-Autos in Zusammenhang mit schlechter Kommunikation zwischen Mensch und Maschine, Überforderung des Bedieners beim Wiedererlangen der manuellen Kontrolle sowie Missbrauch. Die Mensch-Maschine-
Schnittstelle erweist sich also als Problem, das gelöst werden muss, um die Versprechen der Automatisierung zu erfüllen.

Oft wird angenommen, dass hochautomatisierte Fahrzeuge über zwei getrennte Betriebsarten verfügen: manuell und automatisiert. Dies legt nahe, dass die eine Betriebsart die andere ausschließt und der Fahrer im automatisierten Modus keine Kontrolle hat. Diese binäre Sichtweise macht den Übergang zwischen den Betriebsarten zu einem praktisch singulären Ereignis, das mit Rücksicht auf die Grenzen der Automatisierung und der Fahrerbereitschaft sehr vorsichtig gehandhabt werden muss. Bei Jtekt haben wir uns für einen weniger einschränkenden Ansatz entschieden, bei dem sich Fahrer und Fahrzeug die laterale Kontrolle teilen. Durch haptische Mittel werden die Eingaben von Fahrer und Fahrzeug über das Lenksystem harmonisiert, sodass das Automatisierungssystem auf intuitive Art durch manuelle Eingaben übersteuert werden kann. Je nach Fahrer und Verkehrsbedingungen kann das ganze Spektrum zwischen manuellem und vollautomatisiertem Fahren genutzt werden. Die Frage der Übergabezeit wird irrelevant, und der Fahrer muss den automatisierten Modus nicht nach jeder manuellen Bedienung wieder einschalten. Auch die Art und Weise, wie der Fahrzeuginnenraum die Änderung der Betriebsarten widerspiegeln soll, muss neu gedacht werden. 